Max-Planck-Institut für demografische Forschung

Max Planck Institute for Demographic Research

Konrad-Zuse-Strasse 1 - D-18057 Rostock = Germany = Tel +49 (0) 3812081 - 0 - Fax +49 (0) 3812081 - 202 - www.demogr.mpg.de

MPIDR Working Paper WP 2017-009 I April 2017

\title{
Trends in gender differences in health and mortality at working ages among West and East Germans
}

Mine Kühn I kuehn@demogr.mpg.de Christian Dudel I dudel@demogr.mpg.de Tobias Vogt I vogt@demogr.mpg.de Anna Oksuzyan I oksuzyan@demogr.mpg.de

(C) Copyright is held by the authors.

Working papers of the Max Planck Institute for Demographic Research receive only limited review. Views or opinions expressed in working papers are attributable to the authors and do not necessarily reflect those of the Institute. 
Trends in gender differences in health and mortality at working ages among West and East Germans

Mine Kühn*, Christian Dudel*, Tobias Vogt*, Anna Oksuzyan*

* M ax-Planck-Institute for Demographic Research, Rostock, Germany

\begin{abstract}
Before 1990, Germany was divided for more than 40 years. While divided, significant mortality disparities between the populations of East and West Germany emerged. In the years following reunification, East German mortality improved considerably, eventually converging with West German levels. In this study, we explore changes in the gender differences in mortality and health across the eastern and western regions of Germany, using data from the Human M ortality Database for the 19802013 period and from the German Socio-Economic Panel (SOEP) for the 1990-2003 period. We apply random-effects linear regressions to the SOEP data to identify trends in health, measured as selfassessed health satisfaction, after German reunification.

The findings of the analysis indicate that women were substantially less satisfied with their health than men in both West and East Germany, but that the gender gap was larger in East Germany than in West Germany. Furthermore, the results show that the health satisfaction of respondents decreased over time, and that the decline was steeper among men - and particularly among East German men - than among women. Thus, the initial male advantage in health in East and West Germany in the years immediately after reunification diminished over time, and even reversed to become a female advantage in East Germany.

Our results suggest that men suffered more than women from the stressful postreunification changes in the political and social landscape of East Germany. Economic insecurity due to unemployment could have had long-lasting effects on the health of the working-aged population. A partial explanation for our finding that health declined more sharply among East German men than among their female counterparts could be that women have better compensation mechanisms for dealing with psychosocial stress.
\end{abstract}

Keywords: Gender Health Gaps; German reunification; Health satisfaction; German Socio-Economic Panel

Corresponding author: M ine Kühn

Max-Planck-Institute for Demographic Research

Konrad-Zuse Straße 1

18057 Rostock, Germany

Email: kuehn@demogr.mpg.de 


\section{Introduction}

Gender differences in health and mortality have long been of interest to researchers. In 1955, Jeff N. Morris showed that until about 1900, the death rates of English men were only about $10 \%$ higher than those of their same-aged female counterparts; but that in the 1950s, middle-aged English men had death rates that were almost twice as high as those of same-aged women (Morris 1955). An article published in 2006 in the British M edical Journal noted that "even in the poorest countries women were expect to outlive men" (Barford, Dorling et al. 2006). According to UN estimates, these patterns could be observed through 2015, when the gender gap in life expectancy at birth was 3.2 years in low-income countries, 3.8 years in middle-income countries, and 6.2 years in high-income countries (United Nations 2015). In a comparison of low-mortality countries with reliable population statistics, the gender gap in life expectancy in 2013 was found to be largest in the Russian Federation (11.2 years) and smallest in Ireland (3.1 years), with Germany occupying an intermediate position (4.9 years) (HM D 2016).

In the 1970s, C. Nathanson pointed out that despite the consistent female advantage in survival, women tend to be in worse health than their same-aged male counterparts (Nathanson 1975). These seemingly contradictory trends are often referred to as the male-female health-survival paradox (Wingard 1984; Case and Paxson 2005; Oksuzyan, Juel et al. 2008). The research literature on this issue has reported that men do better on physical performance tests than women (Bohannon, Peolsson et al. 2006; Cooper, Hardy et al. 2011), and that males have more functional limitations at all ages than females of the same age (Newman and Brach 1999; M urtagh and Hubert 2004; Palacios-Ceña, JiménezGarcía et al. 2012). It has also been shown that women tend to report being in worse general health than men of the same age (Crimmins and Saito 2001; Dahlin and Härkönen 2013; Oksuzyan, Shkolnikova et al. 2014). The female disadvantage in self-reported health has been found to be larger at younger ages, and to diminish with increasing age (Gorman and Read 2006) and when other health measures are controlled for in the model (Crimmins, Kim et al. 2010). The magnitude of the gender gap in selfreported health varies substantially across European (EU) countries; it is more pronounced in the eastern and the southern EU countries, and it is small or negligible in Denmark and Norway (Crimmins, Kim et al. 2010; Oksuzyan, Crimmins et al. 2010; Dahlin and Härkönen 2013). Although German women and men tend to report having similar levels of general health, German women are more likely than German men to report having health limitations, difficulties performing Instrumental Activities of Daily Living, depression symptoms, hypertension, and arthritis (Crimmins, Kim et al. 2010; Doblhammer and Hoffmann 2010).

It is particularly interesting to analyze the health and mortality patterns of Germany because the country was divided for more than 40 years. The division of Germany between 1949 and 1990 provides us with a unique setting for examining the effects of different socioeconomic and political settings on health and mortality (Vaupel, Carey et al. 2003; Luy 2004): the populations of East and West Germany have a shared culture and history, but they experienced rather different political and socioeconomic conditions while the country was divided. The societal differences that arose during this period have had lasting effects on the mortality levels in both parts of the country. Starting at the end of the 1970s, the mortality levels of older East Germans in particular began to fall behind those of their West German counterparts. Improvements in cardiovascular mortality in West Germany led to lower age-specific risks of death among West German men and women. Since German reunified in 1990, the once-large mortality disadvantage of East Germans has disappeared among women and has narrowed considerably among men (HM D 2016). In particular, East Germans aged 60 and older have seen a marked reduction in 
their risk of death (Vogt 2013). However, large East-West mortality disparities remain among men of working ages, as mortality improvements among these age groups have stagnated. Several studies have attributed the convergence of mortality levels in East and West Germany to the equalization of living conditions, the adaptation of health behaviors, and improvements in health care (Nolte, Shkolnikov et al. 2000; Nolte, Scholz et al. 2002; Kibele 2012; Vogt and Vaupel 2015). These trends may have simultaneously led to a decline in health inequalities between West and East Germany.

The existing literature on the differences in health among West and East Germans has shown that economic factors play an important role (e.g., Razum, Altenhöner et al. 2008; Roeding, Beck et al. 2013). Frijters, Haisken-DeNew et al. (2005) found a positive effect of increasing income on health satisfaction in East Germany. In a study analyzing the relationship between income and poor self-rated health across different welfare state regimes (Sweden, West and East Germany), M iething, Lundberg et al. (2013) found no clear pattern of poor self-rated health among East Germans in the lower household income quintiles, and suggested that East Germany has specific social stratification characteristics that continue to differentiate it from West Germany. In an examination of the effects on health of regional economic factors, such as community income and the labor market, Eibich and Ziebarth (2014) found that these factors have strong and significant associations with individual health. These findings have been explained by evidence showing that following reunification, older East Germans benefited from enormous pension increases and improvements in health care availability, whereas East Germans of working ages suffered from the changes in labor market conditions. Such changes led to destandardization and discontinuity in the life courses of many East Germans, as they experienced repeated phases of unemployment, temporary work, or marginal employment (Easterlin and Plagnol 2008; Simonson, Gordo et al. 2015).

There have, by contrast, been relatively few studies that have focused on the trajectories of gender differences in health in the German population, while taking the special case of German reunification into consideration. In the present study, we analyze gender differences in health among the working-aged populations of East and West Germany, as these groups have been most affected by the changes in the German labor market following reunification. Specifically, we investigate the question of whether the changes in health and mortality since reunification follow similar patterns among East and West German women and men.

Based on previous empirical findings showing that after reunification, the mortality levels of East German women caught up to those of their West German counterparts more quickly than the mortality levels of East German men (Klenk, Rapp et al. 2007; Myrskylä and Scholz 2013), we also expect to find a narrowing of gender differences in health in East Germany. We aim to analyze the male-female differences in health in East and West Germany, and to investigate how this gender gap in health changed over time in the decades following reunification.

\section{Data}

Mortality data

The Human M ortality Database (HMD) contains national-level information on period and cohort deaths rates, life tables, population sizes, and exposures. The underlying data are drawn from different sources, ranging from vital statistics to censuses (www.mortality.org). The HMD provides high quality data, updated regularly, on death rates and life tables for the national populations of 38 countries in Europe, 
North America, Oceania, and Asia. In the present study, we use HMD data to calculate the sex ratios of mortality rates (the ratio of male to female mortality rates) at ages 20 to 59 in the period 1980-2013 by single years of age and calendar years for East and West Germany. This approach allows us to show the evolution of mortality disparities between women and men before and after reunification.

\section{Data on health outcomes}

To examine health trends after reunification and to explore gender differences in health in West and East Germany, we use panel data from the German Socio-Economic Panel (SOEP). The SOEP is a nationally representative longitudinal dataset that covers the population of Germany (Wagner, Frick et al. 2007). The SOEP was initiated in West Germany in 1984. Since then, it has been conducted annually, and includes detailed social and economic information on all individuals aged 16 and older in the respondent households. Our analyses use only SOEP data from 1990 onward, because a sample of East German households was first added to the panel in 1990. We define East and West Germans based on responses to a retrospective question about the place of residence in 1989.

We use the self-assessed level of health satisfaction as the measure of health. The respondents were asked: "How satisfied are you at present with your health situation?" The answers were recorded on a scale of zero ("very unsatisfied") to 10 ("very satisfied"). Previous research has shown that health satisfaction is strongly associated with general health and physical health measures (Butterworth and Crosier 2004), and corresponds closely to self-assessed health (Frijters, Haisken-DeNew et al. 2005); an indicator that is commonly used as a proxy for assessing a respondent's health status, and is considered to be a reliable measure of general health (M artikainen, Aromaa et al. 1999) and a good predictor of future morbidity and mortality (Idler and Benyamini 1997; DeSalvo, Bloser et al. 2006).

To assess the relationship between health satisfaction and self-rated health in our dataset, we calculated Pearson's product-moment correlation and Spearman's correlation coefficient. Both the Pearson's product-moment correlation $(-0.77 ; p<.0005)$ and the Spearman's correlation $(-0.76, p<$ .0005) showed a strong and significant negative correlation between the two health measures. The negative sign is caused by the reverse direction of the measures.

The advantage of using the SOEP health satisfaction measure is that it is available for all years from 1990 to 2013. While the SOEP includes other health measures, these indicators were introduced into the data collection instrument later, and are not available for the whole period of interest. Additional analyses with other health measures were conducted to assess whether they show trends similar to those of the health satisfaction measure (see details in the supplementary materials).

\section{Study population}

Migration between West and East Germany after reunification can be assessed by using the retrospective question about the place of residence in 1989, and by drawing on annual information about the current place of residence. Between 1991 and 2014, 3.4 million East Germans migrated to the West and 2.2 million West Germans migrated to the East (Bundesamt 2015). Most of the individuals who migrated from East to West were young and skilled, and a large proportion of them were women. Meanwhile, the people who stayed in the East tended to be older, in need of care, or low-skilled (Razum, Altenhöner et al. 2008). We assume that the adaptation process occurred more quickly among 
the individuals who migrated from East to West Germany than among those who stayed in East Germany. To avoid selective out-migration effects, we focus on the individuals who had never migrated.

Moreover, to avoid selection effects related to panel attrition caused by serious illness and multi-morbidity, we restrict our data to the working-aged population (aged 20-59). Among people aged 60 and older, panel attrition is mainly due to disease or death; whereas among younger people, panel attrition is mainly due to moving (Lipps 2009).

Analytical strategy

Random-effects linear regressions were applied to examine the trajectories of health satisfaction from 1990 to 2013. Although health satisfaction is measured on an ordinal scale, linear models are usually found to give results that are similar to those of discrete choice models, and that are easier to interpret (Ferrer-i-Carbonell and Frijters 2004; Dudel, Ott et al. 2016). Alternative models are used as robustness checks (see details in the supplementary materials).

\section{Control variables}

In addition to region (East and West Germany), gender is the main explanatory variable of interest, and is included in the multivariate analyses as a dummy (women as reference). To assess trends in health satisfaction in the years after reunification, we control for time as a continuous variable (time = year 1989). Furthermore, all models include (time) ${ }^{2}$ to show non-linear trajectories. To investigate sex differences over time, we add the two-way interaction between sex and time (model 1 and model 2) and the three-way interaction of sex with time and region (model 3).

Age is divided into four categories and is included using dummy variables: (i) 20 to 24 (reference category), (ii) 25 to 29, (iii) 30 to 34, (iv) 35 to 39, (v) 40 to 44, (vi) 45-49, (vii) 50-54, and (viii) 55-59. The logarithmic net equivalent income (as a continuous variable), employment status, and education are also included in the multivariate analyses. Net equivalent income is calculated using the modified OECD scale (Hagenaars, De Vos et al. 1994). Employment status is broken down into five categories: (i) fulltime, (ii) part-time, (iii) marginal employment ${ }^{1}$, (iv) in education, and (v) not employed ${ }^{2}$ (reference category). For education we use the International Standard Classification of Education (ISCED) to distinguish three categories: (i) low (ISCED 0-2), (ii) middle (ISCED 3-4) (reference category), and (iii) high (ISCED 5-6).

\footnotetext{
${ }^{1}$ The expression does not refer to specific working hours per week/month, but rather to a maximum monthly wage of 450 euros.

${ }^{2}$ In addition to individuals who are unemployed and looking for a job, the latter category also includes individuals who are performing military or community service, are on maternity leave, or are in partial retirement and are no longer working.
} 


\section{Main findings}

Descriptive analysis: Mortality

Figure 1 depicts the risk of death among East German men at different ages relative to the risk of death among East German women. Men had a higher risk of death at all ages, but especially at young adult ages. The relative mortality disadvantage of working-aged men rose over time in East Germany. The mortality differences between men and women in East Germany were smaller in 1980 than in the 1990s. In 1980, men in their twenties were 2.5-3.0 more likely to die than women in the same age group. This mortality disadvantage was slightly lower among men aged 30-59: among this age group, men were 1.7-2.1 times more likely to die than women. This pattern compares favorably to the gender mortality differences found for West Germany in the same year. However, among people aged 35 and older, the sex differences declined in West Germany during the 1980s, while they remained stagnant in the East. During this period, the relative risk of death increased most dramatically among East German men of working ages. In 1989, men aged 20-59 were at least twice as likely to die as women in the same age group. This pronounced disadvantage increased markedly after reunification. During the 1990s, the relative mortality risk among men aged 30 and older reached levels that had previously been seen at young adult ages only. Since the end of the 2000s, the gender differences in mortality seem to have narrowed, but men continue to have a much higher risk of death than women. In 2013, East German men were still twice as likely to die as East German women, except among the 35-45 age group. In contrast, among West Germans aged 30 and older, men were only 1.5-1.9 times more likely to die than women. Whereas reunification clearly affected mortality levels among East Germans, no similar pattern can be observed among West Germans. 
Figure 1: Male/ female mortality risk ratios by age for East and West Germany, 1956-2011 (Note: White areas show missing values)
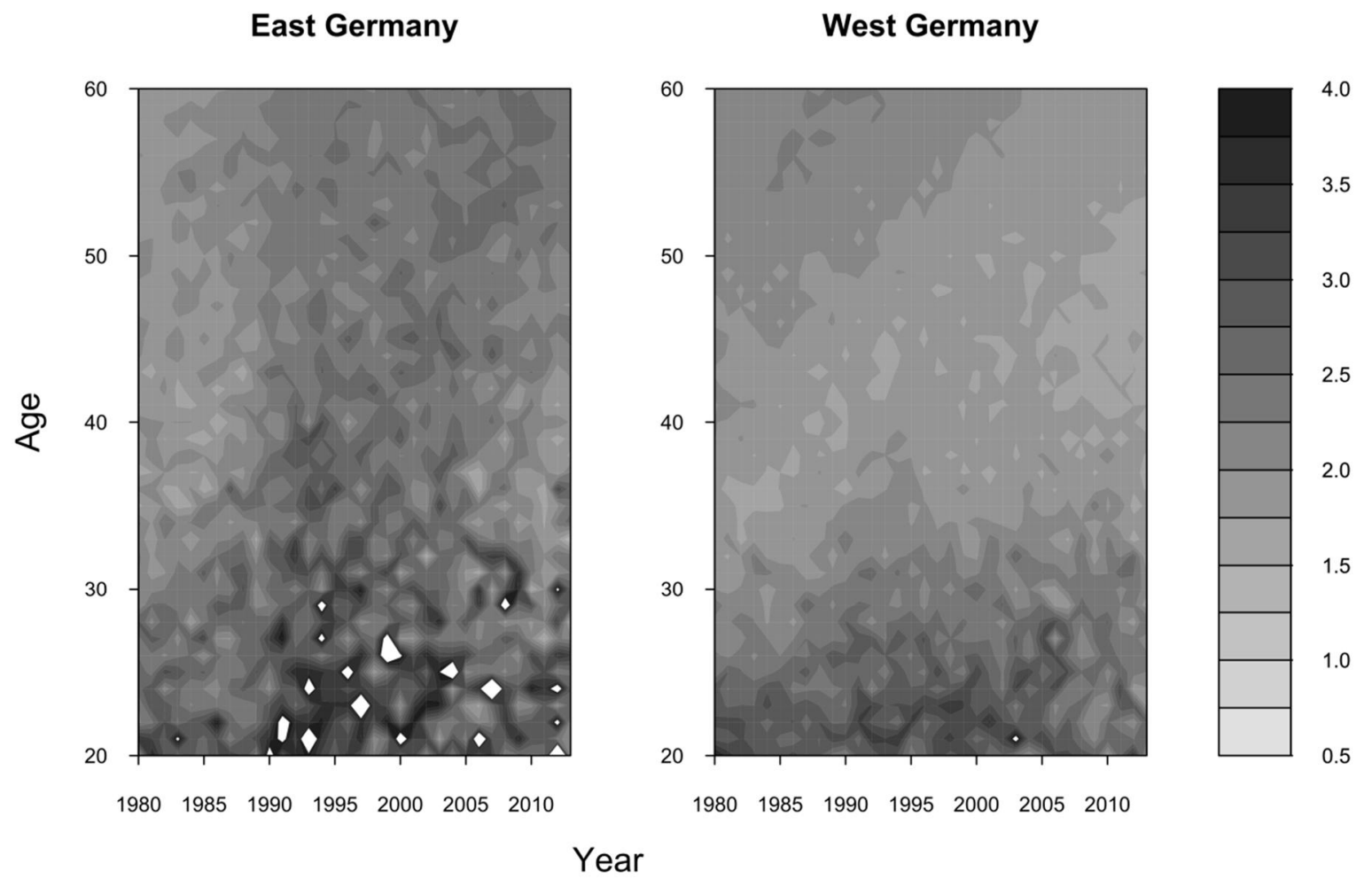

\subsection{Descriptive analysis of health satisfaction}

Figure 2 shows sex-specific trajectories of health satisfaction among West and East Germans, and the absolute male-female differences in health satisfaction in four age groups.

Levels of health satisfaction declined with age in both genders and in both parts of Germany. Among the age groups 40-49 and 50-59, West Germans had higher levels of health satisfaction than East Germans. Among the younger age groups (20-29 and 30-39), East Germans had higher levels of health satisfaction than West Germans in 1990. However, these satisfaction levels decreased among the 20-29-year-olds through the late 1990s and among the 30-39-year-olds through the mid-1990s. A sharp drop in health satisfaction shortly after reunification is observed among all of the age groups in the East German sample, and is particularly pronounced among the 30-39- and 40-49-year-olds. 


\section{Figure 2: Trajectories of sex differences in health satisfaction}
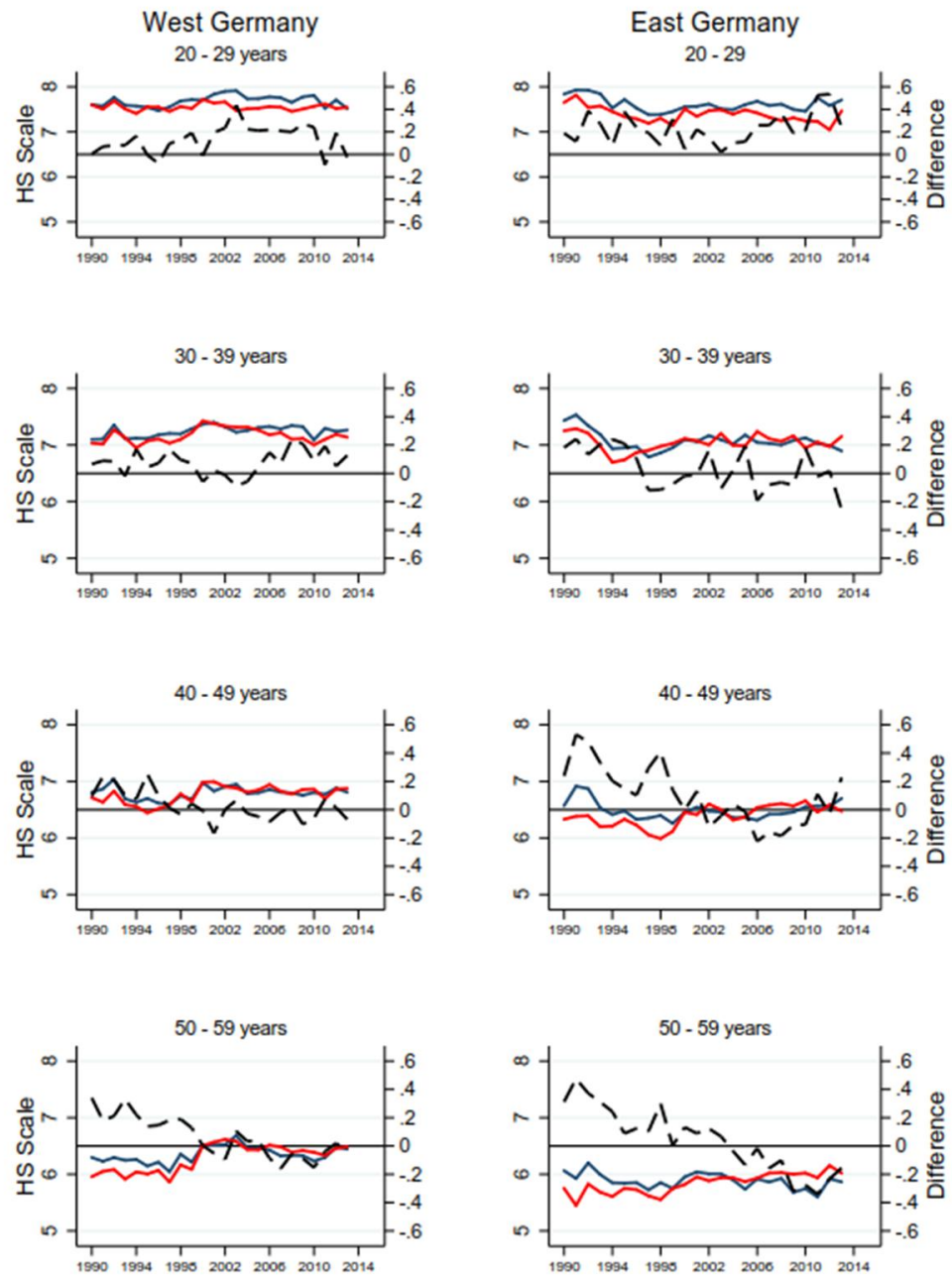

Except among the 20-29- and 30-39-year-old West Germans, the gender gap in health satisfaction favored men during the years immediately after reunification. The gender differences in health satisfaction were particularly large among the 40-49 and 50-59 age groups, and were larger in East than in West Germany. There was a clear narrowing of the gender gap among most of the age groups with time. Over the observation period, health satisfaction was higher among men than among women in both East and West Germany for the youngest age group only. While the gender gap in health satisfaction disappeared in West Germany among the 40-49 and 50-59 age groups in the early 2000s, there was even a cross-over of sex differences in East Germany in the mid-2000s, when a female advantage in health emerged among the 50-59 age group. 
Table 1: Random-effects regression models with sex and time interaction for West and East Germany (1990-2013)

\begin{tabular}{|c|c|c|c|c|}
\hline & \multicolumn{2}{|c|}{ Model 1} & \multicolumn{2}{|c|}{ Model 2} \\
\hline & \multicolumn{2}{|c|}{ West Sample } & \multicolumn{2}{|c|}{ East Sample } \\
\hline & Coeff. & SE & Coeff. & SE \\
\hline Women & $-0.14 * *$ & $(0.05)$ & $-0.25 * * *$ & $(0.07)$ \\
\hline Time & -0.00 & $(0.00)$ & $-0.04 * * *$ & $(0.01)$ \\
\hline$(\text { Time })^{2}$ & $-0.00 * * *$ & $(0.00)$ & 0.00 & $(0.00)$ \\
\hline Women xTime & $0.01 * * *$ & $(0.00)$ & $0.02 * * *$ & $(0.00)$ \\
\hline \multicolumn{5}{|l|}{ Age (reference 20-24) } \\
\hline $25-29$ & $-0.22 * * *$ & $(0.03)$ & $-0.20 * * *$ & $(0.04)$ \\
\hline $30-34$ & $-0.42 * * *$ & $(0.03)$ & $-0.49 * * *$ & $(0.05)$ \\
\hline $35-39$ & $-0.60 * * *$ & $(0.04)$ & $-0.72 * * *$ & $(0.05)$ \\
\hline $40-44$ & $-0.80 * * *$ & $(0.04)$ & $-1.03 * * *$ & $(0.05)$ \\
\hline $45-49$ & $-1.02 * * *$ & $(0.04)$ & $-1.32 * * *$ & $(0.05)$ \\
\hline $50-54$ & $-1.25 * * *$ & $(0.04)$ & $-1.57 * * *$ & $(0.06)$ \\
\hline $55-59$ & $-1.46 * * *$ & $(0.04)$ & $-1.86 * * *$ & $(0.06)$ \\
\hline \multicolumn{5}{|l|}{ Employment status (reference: non-employed) } \\
\hline Full-time & $0.14 * * *$ & $(0.02)$ & $0.20 * * *$ & $(0.03)$ \\
\hline Part-time & $0.08 * *$ & $(0.03)$ & $0.14 * * *$ & $(0.04)$ \\
\hline In education & 0.05 & $(0.05)$ & $0.14 *$ & $(0.06)$ \\
\hline Marginally & $0.07 *$ & $(0.03)$ & 0.02 & $(0.06)$ \\
\hline (log) net equivalent income & $0.21 * * *$ & $(0.02)$ & $0.22 * * *$ & $(0.03)$ \\
\hline \multicolumn{5}{|l|}{ Education (reference: ISCED 3-4 M iddle) } \\
\hline ISCED 0-2 Low & $-0.11 * * *$ & $(0.03)$ & $-0.13 *$ & $(0.06)$ \\
\hline ISCED 5-6 High & $0.14 * * *$ & $(0.03)$ & 0.07 & $(0.05)$ \\
\hline Constant & $5.82 * * *$ & $(0.19)$ & $5.78 * * *$ & $(0.31)$ \\
\hline Observatio & \multicolumn{2}{|c|}{119144} & \multicolumn{2}{|c|}{50300} \\
\hline $\mathrm{R}^{2}$ & \multicolumn{2}{|c|}{0.06} & \multicolumn{2}{|c|}{0.11} \\
\hline
\end{tabular}

Standard errors in parentheses

$* p \varangle 0.05, * * p \varangle 0.01, * * * p \varangle 0.001$

Multivariate analysis of health satisfaction

Table 1 shows the results of the random-effects regression models. To identify regional-specific determinants of health satisfaction, we ran separate models for West and East Germany. The results suggest that women were far less satisfied with their health than men in both West and East Germany. However, the gender gap in health was larger in East than in West Germany. Furthermore, the results show a small but significant negative period effect among East Germans, which indicates that health satisfaction among these respondents declined over time. The interaction between sex and time is positive, which suggests that health satisfaction declined less steeply over time among women than among men.

The coefficients for the other control variables shown in Table 1 are in the expected direction. The effect of age is large and negative, which indicates that health satisfaction declined with age. There 
is a significant positive effect of being employed (full-time or part-time) and of having a higher income and a higher education; although the latter effect is significant in West Germany only.

Since the quadratic effect of time in the model is difficult to interpret, we provide Figure 3 , in which the predicted health satisfaction levels based on model 1 and model 2 from Table 1 are shown (upper figure).

Figure 3: Predicted health satisfaction
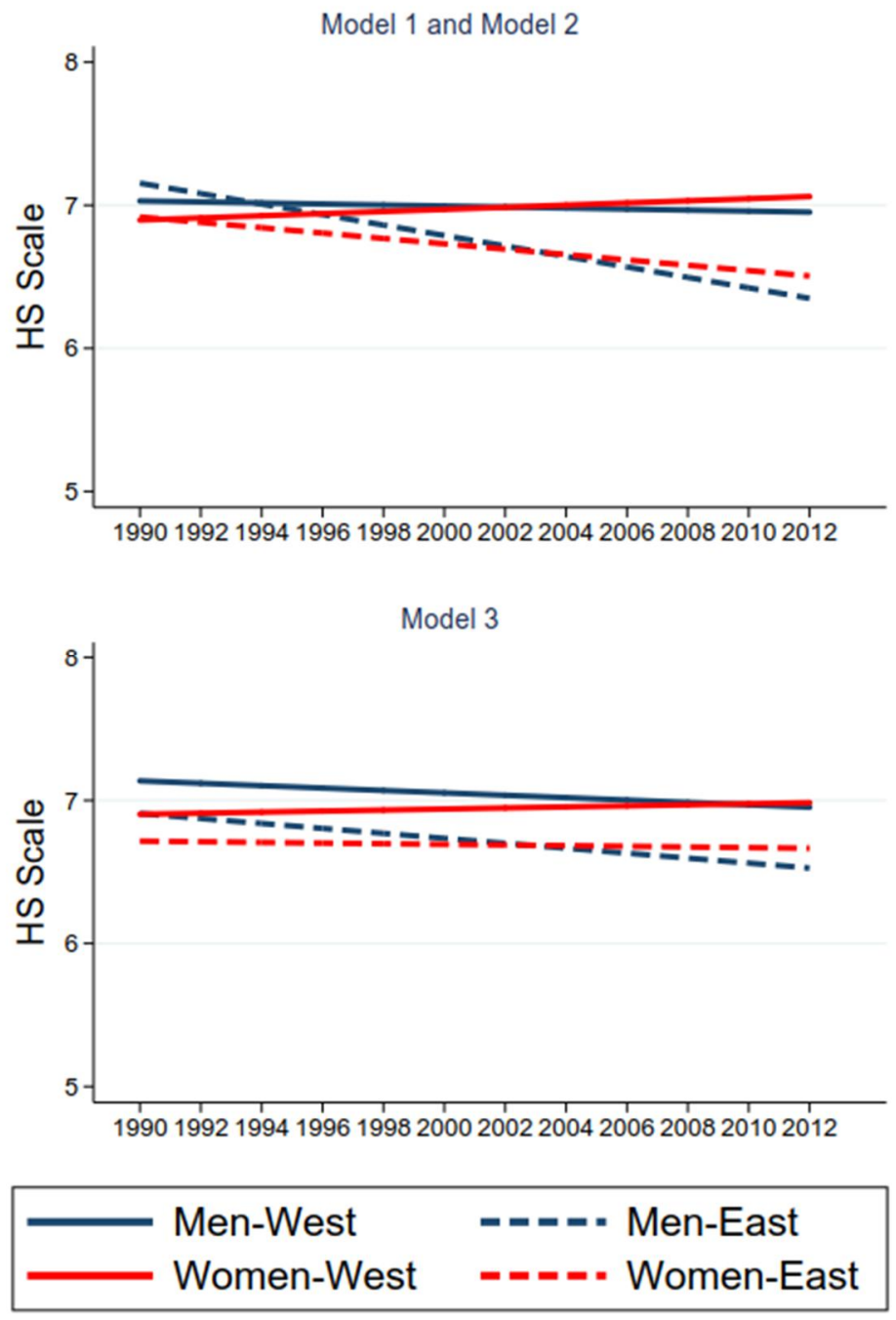

Looking at the figure, we can see that over the study period, health satisfaction declined among both women and men in the East German sample, while there was no decline among women and a very small decline among men in the West German sample. We can also observe that in both samples, the male advantage in health satisfaction was large in the years immediately following reunification, but diminished over time. Moreover, it is apparent that after a cross-over in the early 2000s, a female advantage in health satisfaction emerged in both samples. 
To take regional differences into account as well, we pool the data and include the three-way interaction of sex, region, and time (Supplementary Table 2). The special feature of this pooled model is that it allows us to estimate the joint effect of these three variables on health satisfaction, and thus to compare the trajectories in health satisfaction of the subgroups.

Figure 3 (Model 3) shows that among all of the subgroups, East German men had the largest decline in health satisfaction, and that levels of health satisfaction were higher among West Germans than among East Germans. The regional gap in health widened over time, particularly among men.

In this model, we also observe a diminishing gender gap in health satisfaction after reunification. However, there were differences between West and East Germany in the timing of the cross-over and in the extent of the female advantage.

\section{Discussion}

Main Findings

In this paper, we showed that since reunification, the gender gap in mortality has widened in East Germany, but not in West Germany. Our examination of health satisfaction levels indicated that there was a pronounced gender gap favoring men in the years immediately after reunification, but that the male advantage diminished over time, and even reversed to become a female advantage in East Germany.

The widening gender differences in mortality can be explained by the greater improvements in mortality among East German women than among East German men. The question of why female mortality responded differently than male mortality to the changes in living conditions remains open. A study by Myrskylä and Scholz (2013) has suggested that rapid improvements in female mortality are likely attributable to women's lower tobacco consumption before reunification.

As was previously noted, working-aged East Germans suffered from the effects of soaring unemployment and economic insecurity following reunification. It is possible that East Germans in this age group adopted unhealthy behaviors that led to an increase in mortality from "man-made" causes of death. East German men continue to smoke more and to consume more alcohol than East German women (Robert Koch-Institut 2009). These unfavorable lifestyle choices may also be responsible for the higher levels of male mortality in East than in West Germany. The convergence of male mortality among younger age groups seems to have stopped among populations in rural areas and smaller towns with poor economic prospects (Kibele, Klüsener et al. 2015; Vogt and Vaupel 2015). These general changes in health behaviors and in economic prospects during the 1990s may be reflected in the health trajectories of East German men and women.

The trajectories of gender differences in health indicate that there was an overall - albeit diminishing - male advantage in health satisfaction in East and West Germany over the study period. The predicted health satisfaction trajectories based on panel regression models showed a reversal of the gender gap in health and the emergence of a female advantage in health later in the study period, particularly among East Germans. While mortality improved substantially in East Germany, there were no apparent improvements in health, especially among East German men. As a result of this decline in health, within-gender regional differences in health increased as well. In contrast to previous research 
(e.g., Razum, Altenhöner et al. 2008; Roeding, Beck et al. 2013), we found a widening regional gap in health in favor of West Germans that was smaller for women and larger for men.

The decline in health among East German men can be partially explained by the differences in health behavior mentioned above, which we could not control for due to the unavailability of these data in the SOEP. Another potential explanation is related to the effects of the post-reunification economic changes in East Germany. Although Easterlin and Plagnol (2008) did not distinguish between East German men and women, they demonstrated that life satisfaction in post-reunification East Germany declined until the late 1990s because of the deterioration in economic conditions.

It appears that unemployment had a substantial impact on the health trends among women and men in East and West Germany. A number of studies have shown that unemployment is associated with adverse mental and physical health, unfavorable lifestyles, and increased mortality risk (McKee-Ryan, Song et al. 2005; Cohen, Kemeny et al. 2007; Virtanen, Vahtera et al. 2008; Roelfs, Shor et al. 2011; Leist, Glymour et al. 2013). Although a growing body of research has suggested that unemployment has different effects on health in men than in women, the findings of these studies have been inconsistent. Contradictory results have, for example, been found for the likelihood of using more alcohol and tobacco after becoming unemployed. While some studies have uncovered a relationship between unemployment and increased alcohol consumption and smoking in unemployed men only (Reine, Novo et al. 2013), a Swedish study found that this association was attenuated in women after controlling for having children (De Vogli and Santinello 2005; Bolton and Rodriguez 2009). An international comparison has shown that the effects of unemployment on the health of men and women differ in Ireland and in Sweden. This finding suggests that the positions and the roles of men and women in the labor market and in the family are important factors in explanations of the negative consequences of unemployment on health (Strandh, Hammarström et al. 2013).

Our results indicate that men suffered more than women from the stressful changes that occurred in the political and social landscape of East Germany after reunification. Economic insecurity due to unemployment might have had long-lasting effects on health, particularly among the workingaged group analyzed here. A partial explanation for the steeper decline in health among East German men than among East German could be that women have better compensation mechanisms for coping with psychosocial stress (Kibele 2012).

\section{Methodological considerations}

For our analyses on mortality and health, we made use of two data sources. The mortality data were derived from a high quality data source that is widely used in demographic research, the Human Mortality Database. The second data source was the German SOEP. While SOEP data have been successfully used to study many different topics, they have some limitations. Most importantly, our findings might be affected by selective panel attrition. Previous literature has shown that attrition is correlated with worsening health (Lugtig 2014), which could lead to biased estimates. An exploratory analysis of our data suggests that this is unlikely to the case here, as health satisfaction levels tend to be similar among respondents who remain in or drop out of the study (Supplementary Table 3). However, we cannot rule out the possibility that the individuals who dropped out of the panel did worse in the long run than those who remained in the sample. Furthermore, in the present study we can use only the SOEP data from 1990 onward. Thus, we were not able to use the data to examine the exogenous shock caused by unification. 
Another methodological limitation that is inherent in all panel studies is panel conditioning effects, which arise when respondents are influenced by having participated in previous surveys or waves (Das, Toepoel et al. 2011). Such effects could bias the results (Wooden and Li 2014). Based on the SOEP data, Schupp, Goebel et al. (2013) showed that a correction for panel conditioning slightly affects the level of life satisfaction, but does not affect its trajectory. Even though health satisfaction was not included in their analyses, we can expect that panel conditioning would have no significant impact on health satisfaction trajectories.

Another potential limitation is that while the reliability of other health measures had been tested, there are few studies that have tested the reliability of self-assessed health satisfaction. We therefore conducted additional analyses with both self-rated health and the SF-12v2 (Supplementary Table 4). Our findings show that the patterns of health trajectories by region and gender are similar for both measures, which suggests that health satisfaction can be used as a proxy measure.

Another potential issue involves the multivariate analyses. While the random-effects models we employed can control for unobserved time-constant heterogeneity, they rely on the assumption that the unobserved heterogeneity is not correlated with any of the observed characteristics. For instance, it is assumed that unobserved heterogeneity is not correlated with gender. We therefore estimated linear fixed-effects regressions that do not rest on this strong assumption as a robustness check (Supplementary Table 5). The coefficient estimates are generally similar to the random-effects estimates with respect to sign and magnitude.

Overall, while we cannot completely rule out the possibility that our analyses are affected by the issues outlined above, our robustness checks using alternative modeling strategies and alternative health measures generated results consistent with our main findings.

\section{Conclusion}

In this study, we analyzed gender gaps in health and mortality among the German population after reunification. The results suggest that East German men have benefited from reunification less than East German women. There is a clear widening of the gender gap in mortality in favor of East German women. Moreover, whereas men are generally healthier than women, the male advantage in health in East Germany diminished over time, and even turned into a health disadvantage. These findings imply that while the male-female paradox in health and mortality was apparent in the years immediately after reunification, it was less pronounced at the end of the study period.

$M$ ore research into the causes of death is needed to explain the widening of the sex differences in mortality in East Germany and to derive policy implications. When objective health measures derived from, for example, German health insurance data become available, they can be used to examine whether the trajectories of health follow patterns similar to those of health satisfaction. Furthermore, these data can enable us to examine other mechanisms that could underlie the steeper health decline in men, such as differential treatment-seeking behavior and/or differences in the distribution of acute lifethreating and non-acute disabling conditions in men and women. 


\section{References}

Allison, P. D. (2009). Fixed effects regression models, SAGE publications.

Andersen, H. H., A. Mühlbacher, et al. (2007). "Computation of standard values for physical and mental health scale scores using the SOEP version of SF-12v2." Schmollers Jahrbuch 127(1): 171-182.

Barford, A., D. Dorling, et al. (2006). "Life expectancy: women now on top everywhere." BM] 332: 808-808.

Bohannon, R. W., A. Peolsson, et al. (2006). "Reference values for adult grip strength measured with a Jamar dynamometer: a descriptive meta-analysis." Physiotherapy 92(1): 11-15.

Bolton, K. L. and E. Rodriguez (2009). "Smoking, drinking and body weight after re-employment: does unemployment experience and compensation make a difference?" BM C Public Health 9(1): 77.

Bundesamt, S. (2015). Wanderungssaldo 2014 von Ost nach West mit 3300 Personen nahezu ausgeglichen.

Butterworth, P. and T. Crosier (2004). "The validity of the SF-36 in an Australian National Household Survey: demonstrating the applicability of the Household Income and Labour Dynamics in Australia (HILDA) Survey to examination of health inequalities." BM C Public Health 4(1): 1-11.

Case, A. and C. Paxson (2005). "Sex differences in morbidity and mortality." Demography 42(2): 189-214.

Cohen, F., M. E. Kemeny, et al. (2007). "Immune function declines with unemployment and recovers after stressor termination." Psychosomatic M edicine 69(3): 225-234.

Cooper, R., R. Hardy, et al. (2011). "Age and gender differences in physical capability levels from mid-life onwards: the harmonisation and meta-analysis of data from eight UK cohort studies." PLOS ONE 6(11): e27899.

Crimmins, E. M., J. K. Kim, et al. (2010). "Gender differences in health: results from SHARE, ELSA and HRS." The European Journal of Public Health 21: 81-91.

Crimmins, E. M. and Y. Saito (2001). "Trends in healthy life expectancy in the United States, 1970-1990: gender, racial, and educational differences." Social Science \& M edicine 52(11): 1629-1641.

Dahlin, J. and J. Härkönen (2013). "Cross-national differences in the gender gap in subjective health in Europe: Does country-level gender equality matter?" Social Science \& M edicine 98: 24-28.

Das, M., V. Toepoel, et al. (2011). "Nonparametric tests of panel conditioning and attrition bias in panel surveys." Sociological Methods \& Research 40(1): 32-56.

De Vogli, R. and M. Santinello (2005). "Unemployment and smoking: does psychosocial stress matter?" Tobacco control 14(6): 389-395.

DeSalvo, K. B., N. Bloser, et al. (2006). "Mortality prediction with a single general self-rated health question." Lournal of General Internal Medicine 21(3): 267-275.

Doblhammer, G. and R. Hoffmann (2010). "Gender differences in trajectories of health limitations and subsequent mortality. A study based on the German Socioeconomic Panel 1995-2001 with a mortality follow-up 20022005." Journal of Gerontology: Social Sciences 65(4): 482-491.

Dudel, C., N. Ott, et al. (2016). "M aintaining one's living standard at old age: What does that mean?" Empirical Economics online first(Journal Article).

Easterlin, R. A. and A. C. Plagnol (2008). "Life satisfaction and economic conditions in East and West Germany preand post-unification." Journal of Economic Behavior \& Organization 68(3): 433-444.

Eibich, P. and N. Ziebarth (2014). "Examining the Structure of Spatial Health Effects using Hierarchical Bayes Models." Regional Science and Urban Economics(F07-V1).

Ferrer-i-Carbonell, A. and P. Frijters (2004). "How Important is Methodology for the estimates of the determinants of Happiness?" The Economic Journal 114(497): 641-659.

Frijters, P., J. P. Haisken-DeNew, et al. (2005). "The causal effect of income on health: Evidence from German reunification." \ournal of Health Economics 24(5): 997.

Gorman, B. K. and J. N. G. Read (2006). "Gender Disparities in Adult Health: An Examination of Three Measures of Morbidity*." Journal of Health and Social Behavior 47(2): 95-110.

Hagenaars, A. J., K. De Vos, et al. (1994). "Poverty statistics in the late 1980s: Research based on micro-data."

HMD (2016). Human Mortality Database. USA) and Max- Planck- Institut for Demographic Research, Rostock (Germany, University of California, Berkeley; University of California, Berkeley (USA) M ax- Planck- Institute for Demographic Research, Rostock (Germany).

Idler, E. L. and Y. Benyamini (1997). "Self-Rated Health and Mortality: A Review of Twenty-Seven Community Studies." Journal of Health and Social Behavior 38(1): 21-37. 
Kibele, E. U., S. Klüsener, et al. (2015). "Regional mortality disparities in germany." KZfSS Kölner Zeitschrift für Soziologie und Sozialpsychologie 67: 241-270.

Kibele, E. U. B. (2012). Regional mortality differences in Germany, Springer Science \& Business M edia.

Klenk, J., K. Rapp, et al. (2007). "Increasing life expectancy in Germany: quantitative contributions from changes in age- and disease-specific mortalityt." European Journal of Public Health 17(6): 587-592.

Leist, A. K., M. M. Glymour, et al. (2013). "Time away from work predicts later cognitive function: differences by activity during leave." Annals of Epidemiology 23(8): 455-462.

Lipps, 0. (2009). "Attrition of households and individuals in panel surveys." SOEPpaper 164.

Lugtig, P. (2014). "Panel attrition: separating stayers, fast attriters, gradual attriters, and lurkers." Sociological Methods \& Research 43(4): 699-723.

Luy, M. (2004). "M ortality differences between Western and Eastern Germany before and after Reunification A macro and micro level analysis of developments and responsible factors." Genus 60(3/4): 99-141.

Martikainen, P., A. Aromaa, et al. (1999). "Reliability of perceived health by sex and age." Social Science \& Medicine 48(8): 1117-1122.

McKee-Ryan, F., Z. Song, et al. (2005). "Psychological and physical well-being during unemployment: a metaanalytic study." \ournal of Applied Psychology 90(1): 53-76.

Miething, A., O. Lundberg, et al. (2013). "Income and health in different welfare contexts: A comparison of Sweden, East and West Germany." Scandinavian Journal of Public Health 41(3): 260-268.

Morris, J. N. (1955). "Uses of Epidemiology." British Medical Journal 2(4936): 395-401.

Murtagh, K. N. and H. B. Hubert (2004). "Gender differences in physical disability among an elderly cohort." American Journal of Public Health 94(8): 1406-1411.

Myrskylä, M. and R. Scholz (2013). "Reversing East-West mortality difference among German women, and the role of smoking." International Journal of Epidemiology 42(2): 549-558.

Nathanson, C. A. (1975). "Illness and the feminine role: a theoretical review." Social Science \& Medicine (1967) 9(2): 57-62.

Newman, A. B. and J. S. Brach (1999). "Gender gap in longevity and disability in older persons." Health(1).

Nolte, E., R. Scholz, et al. (2002). "The contribution of medical care to changing life expectancy in Germany and Poland." Social Science and Medicine 55: 1905-1921.

Nolte, E., V. Shkolnikov, et al. (2000). "Changing mortality patterns in East and West Germany and Poland. II: Shortterm trends during transition and in the 1990s." Journal of Epidemiology and Community Health 54(12): 899-906.

Oksuzyan, A., E. Crimmins, et al. (2010). "Cross-national comparison of sex differences in health and mortality in Denmark, Japan and the US." European Journal of Epidemiology 25(7): 471-480.

Oksuzyan, A., K. Juel, et al. (2008). "M en: good health and high mortality. Sex differences in health and aging." Aging Clinical and Experimental Research 20(2): 91-102.

Oksuzyan, A., M. Shkolnikova, et al. (2014). "Sex differences in health and mortality in Moscow and Denmark." European Journal of Epidemiology 29(4): 243-252.

Palacios-Ceña, D., R. Jiménez-García, et al. (2012). "Has the prevalence of disability increased over the past decade (2000-2007) in elderly people? A Spanish population-based survey." Lournal of the American Medical Directors Association 13(2): 136-142.

Razum, O., T. Altenhöner, et al. (2008). "Social Epidemiology after the German Reunification: East vs. West or Poor vs. Rich?" International Journal of Public Health 53(1): 13-22.

Reine, I., M. Novo, et al. (2013). "Unemployment and ill health-A gender analysis: Results from a 14-year follow-up of the Northern Swedish Cohort." Public Health 127(3): 214-222.

Robert Koch-Institut (2009). "20 Jahre nach dem Fall der Mauer: Wie hat sich die Gesundheit in Deutschland entwickelt." Beiträge zur Gesundheitsberichterstattung des Bundes. RKI, Berlin: 71-75.

Roeding, D., D. Beck, et al. (2013). "Zusammenhlange zwischen dem soziolokonomischen Status und dem selbstberichteten Gesundheitszustand der Bevölkerung in nordostdeutschen Landgemeinden 1973, 1994 und 2004/2008." Bundesgesundheitsblatt - Gesundheitsforschung - Gesundheitsschutz 56(10): 13761384.

Roelfs, D. J., E. Shor, et al. (2011). "Losing life and livelihood: a systematic review and meta-analysis of unemployment and all-cause mortality." Social Science \& Medicine 72(6): 840-854. 
Schupp, J., J. Goebel, et al. (2013). "Zufriedenheit in Deutschland so hoch wie nie nach der Wiedervereinigung: Ostdeutsche signifikant unzufriedener als Westdeutsche." DIW-Wochenbericht 80(47): 34-43.

Simonson, J., L. R. Gordo, et al. (2015). "Separate paths, same direction? De-standardization of male employment biographies in East and West Germany." Current Sociology 63(3): 387-410.

Strandh, M., A. Hammarström, et al. (2013). "Unemployment, gender and mental health: the role of the gender regime." Sociology of Health \& IIIness 35(5): 649-665.

United Nations, D. o. E. a. S. A., Population Division (2015). World Population Prospects: The 2015 Revision, Volume II: Demographic Profiles (ST/ESA/SER.A/380).

Vaupel, J. W., J. R. Carey, et al. (2003). "It's Never Too Late." Science 301(Journal Article): 1679-1681.

Virtanen, P., J. Vahtera, et al. (2008). "Employment trajectory as determinant of change in health-related lifestyle: the prospective HeSSup study." The European Journal of Public Health 18(5): 504-508.

Vogt, T. (2013). "How Many Years of Life Did the Fall of the Berlin Wall Add? A Projection of East German Life Expectancy." Gerontology 59(Journal Article): 276-282.

Vogt, T. and J. Vaupel (2015). "The importance of regional availability of health care for old age survival - Findings from German reunification." Population Health Metrics 13(1): 26.

Wagner, G., J. Frick, et al. (2007). "The German Socio-Economic Panel Study (SOEP) - Evolution, Scope and Enhancements." SOEPpaper $\mathbf{1}$ (Journal Article).

Ware, J. E., M. Kosinski, et al. (2002). "How to score version 2 of the SF-12 Health Survey (with a supplement documenting version 1) Lincoln." Rl: QualityM etric Incorporated.

Wingard, D. L (1984). "The sex differential in morbidity, mortality, and lifestyle." Annual Review of Public Health 5(1): 433-458.

Wooden, M. and N. Li (2014). "Panel conditioning and subjective well-being." Social Indicators Research 117(1): 235-255. 
Supplementary Table 2: Radom-effects regression models with sex, time and region interaction for West and East Germany (1990-2013)

\begin{tabular}{|c|c|c|}
\hline & \multicolumn{2}{|c|}{$\begin{array}{c}\text { Model } 3 \\
\text { East and West }\end{array}$} \\
\hline & Coeff. & SE \\
\hline Women & $-0.18 * * *$ & $(0.04)$ \\
\hline Time & $-0.02 * * *$ & $(0.01)$ \\
\hline$(\text { Time })^{2}$ & $0.00 * *$ & $(0.00)$ \\
\hline East in 1989 & $-0.18 * * *$ & $(0.04)$ \\
\hline Women East $x$ Time & $0.02 * * *$ & $(0.00)$ \\
\hline Men West x Time & $0.01 * *$ & $(0.00)$ \\
\hline Women West x Time & $0.02 * * *$ & $(0.00)$ \\
\hline \multicolumn{3}{|l|}{ Age (reference 20-24) } \\
\hline $25-29$ & $-0.21 * * *$ & $(0.02)$ \\
\hline $30-34$ & $-0.44 * * *$ & $(0.03)$ \\
\hline $35-39$ & $-0.63 * * *$ & $(0.03)$ \\
\hline $40-44$ & $-0.87 * * *$ & $(0.03)$ \\
\hline $45-49$ & $-1.11 * * *$ & $(0.03)$ \\
\hline $50-54$ & $-1.35^{* * *}$ & $(0.03)$ \\
\hline $55-59$ & $-1.59 * * *$ & $(0.03)$ \\
\hline \multicolumn{3}{|l|}{$\begin{array}{l}\text { Employment status (reference: non- } \\
\text { employed) }\end{array}$} \\
\hline Full-time & $0.16 * * *$ & $(0.02)$ \\
\hline Part-time & $0.10 * * *$ & $(0.02)$ \\
\hline In education & $0.09 *$ & $(0.04)$ \\
\hline Marginally & $0.07 *$ & $(0.03)$ \\
\hline (log) net equivalent income & $0.21 * * *$ & $(0.02)$ \\
\hline \multicolumn{3}{|l|}{ Education (reference: ISCED 3-4 M iddle) } \\
\hline ISCED 0-2 Low & $-0.12 * * *$ & $(0.03)$ \\
\hline ISCED 5-6 High & $0.12 * * *$ & $(0.02)$ \\
\hline Constant & $5.84 * * *$ & $(0.16)$ \\
\hline Observations & \multicolumn{2}{|c|}{169444} \\
\hline $\mathrm{R}^{2}$ & \multicolumn{2}{|c|}{0.08} \\
\hline
\end{tabular}

Standard errors in parentheses

$* p \varangle 0.05, * * p \varangle 0.01, * * * p \varangle 0.001$ 


\section{Panel Attrition}

The reason why we restricted our analyses to the working-aged population (aged 20-59) is to avoid biased results due to panel attrition. To assess whether the individuals who dropped out of our sample had worse health than those who stayed, we conducted an additional analysis.

Table 3 shows the average health satisfaction levels among those who remained in our sample, those who dropped out at some point, and those who dropped out due to death. Health satisfaction is based on the last contact before dropping out. The results indicate that, on average, the health satisfaction levels were similar among the drop-outs and among the remaining respondents. The opposite is the case for those who dropped out due to death. On average, those respondents were in worse health than those who stayed in the panel. But because deaths are relatively rare in the 20-59 age group, this should not bias our findings.

Supplementary Table 3: Panel attrition and health satisfaction: 20-59-year-olds

\begin{tabular}{lcccccc}
\hline & \multicolumn{3}{c}{ M en } & \multicolumn{3}{c}{ Women } \\
\hline & Mean & SD & $\mathrm{N}$ & M ean & SD & $\mathrm{N}$ \\
\hline Remain in & & & & & & \\
Panel & 6.76 & 2.13 & 4,609 & 6.77 & 2.14 & 5,158 \\
Dropout & 6.92 & 2.10 & 5,675 & 6.90 & 2.10 & 5,640 \\
Death & 4.51 & 2.91 & 315 & 3.99 & 2.97 & 179 \\
\hline
\end{tabular}

Health outcomes

To assess whether other health measures show trends similar to the trends in health satisfaction, we use self-rated health (1992-2013) and the SF-12v2 (2002-2012) (Wagner, Frick et al. 2007), a short form of the SF-36 questionnaire on health-related quality of life (Ware, Kosinski et al. 2002). Self-rated health is measured in five categories ranging from one ("very good") to five ("poor"). We dichotomized the variable with the response options "not so good" and "poor" defined as poor health, and applied a random effects logistic regression model that includes the same covariates as in our main model. Since the coefficients are related to the logarithm of the odds of poor health, a positive coefficient means that the risk of poor health is increasing, while a negative coefficient indicates the opposite. The results, which are shown in Table 4, suggest that over time, the risk of poor health increases and that East German men have the highest probability of being poor health. This in turn suggests that the trajectories of health satisfaction and self-rated health by region and gender are similar to those in our main findings.

The SF-12v2 outcome variable is based on a questionnaire that covers physical and mental health (Andersen, M ühlbacher et al. 2007). Both physical and mental health are measured on a scale of zero to 100 . We apply linear random effects regression to each of these variables, and include the same covariates as in our main model. In comparing the results for the health satisfaction and the SF-12v2 variables, it is important to note that the scales of the variables differ (health satisfaction: zero to 10 versus sf-12: zero to 100). Unlike the estimates for health satisfaction, the estimates for physical and mental health show improvement over time. Thus, the overall trend in the SF-12v2 health measures goes in a different direction than the trend in the health satisfaction measure, but the differences between the genders and between East and West Germany are the same. 


\section{Supplementary Table 4: Estimations with self-rated health and SF-12}

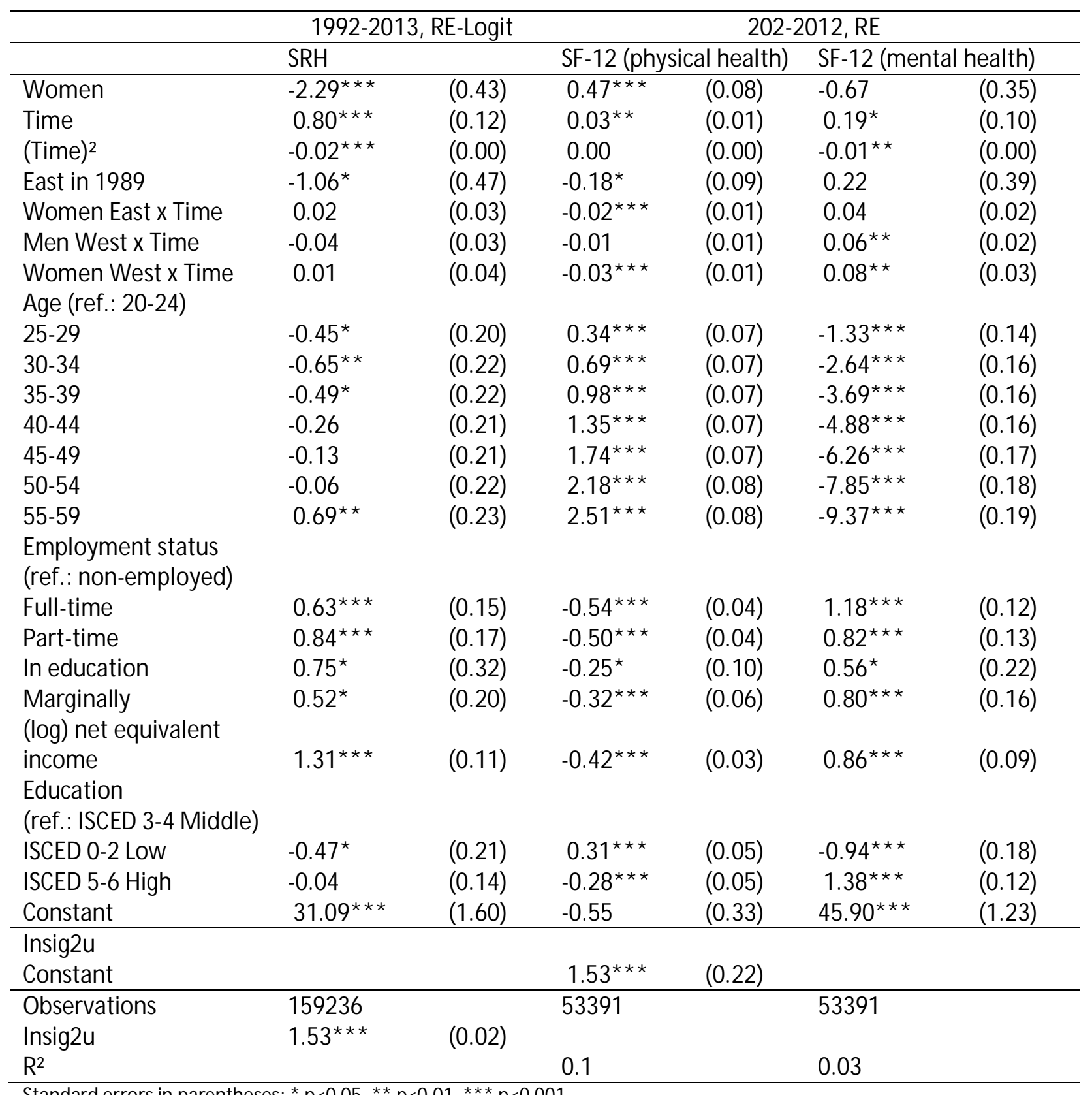

Standard errors in parentheses; $* p \varangle 0.05,{ }^{* *} p \varangle 0.01, * * * p<0.001$

Fixed effects versus random effects

Random-effects and fixed-effects linear regression allow us to control for unobserved heterogeneity; i.e., for unobserved variables that could affect the outcome. Both methods assume that unobserved heterogeneity is time-constant (Allison 2009). Random-effects regression requires that unobserved variables are independent of observed control variables, while fixed-effects regression avoids this restrictive assumption. On the other hand, the fixed-effects approach cannot include time-constant 
explanatory variables and cannot appropriately control for both time and age due to multicollinearity issues, which arise because of its specific setup (e.g., Frijters, Haisken-DeNew et al. 2005).

Using the same covariates as the models in subsection 3.3, linear fixed-effects regressions were estimated as a robustness check. The results are shown in Table 5. A comparison of the results shows that the random-effects and the fixed-effects regression models both suggest a decreasing trend in health satisfaction, with East German men having the steepest decrease over time. However, the trend over time is stronger in the FE model than in the RE model because the negative effect of age on health is mostly captured by the coefficients for the year due to the multicollinearity of age and period.

Supplementary Table 5: Fixed-effects regression models with sex and time (and region) interaction (1990-2013)

\begin{tabular}{|c|c|c|c|c|c|c|}
\hline & \multicolumn{2}{|c|}{ West Sample } & \multicolumn{2}{|c|}{ East Sample } & \multicolumn{2}{|c|}{ East and West } \\
\hline & Coeff. & SE & Coeff. & SE & Coeff. & SE \\
\hline Time & $-0.05 * * *$ & $(0.01)$ & $-0.10 * * *$ & $(0.01)$ & $-0.08 * * *$ & $(0.01)$ \\
\hline$(\text { Time })^{2}$ & $-0.00 * *$ & $(0.00)$ & $0.00 *$ & $(0.00)$ & -0.00 & $(0.00)$ \\
\hline Women x Time & $0.01 * * *$ & $(0.00)$ & $0.02 * * *$ & & & \\
\hline Women East $x$ Time & & & & & $0.02 * * *$ & $(0.00)$ \\
\hline Men West x Time & & & & & $0.01 * *$ & $(0.00)$ \\
\hline $\begin{array}{l}\text { Women West x Time } \\
\text { Age (ref.: 20-24) }\end{array}$ & & & & & $0.03 * * *$ & $(0.00)$ \\
\hline $25-29$ & 0.03 & $(0.03)$ & 0.09 & $(0.05)$ & 0.05 & $(0.03)$ \\
\hline $30-34$ & 0.07 & $(0.05)$ & 0.09 & $(0.07)$ & $0.08 *$ & $(0.04)$ \\
\hline $35-39$ & 0.10 & $(0.06)$ & 0.15 & $(0.08)$ & $0.12^{*}$ & $(0.05)$ \\
\hline $40-44$ & 0.10 & $(0.07)$ & 0.11 & $(0.10)$ & 0.11 & $(0.06)$ \\
\hline $45-49$ & 0.09 & $(0.08)$ & 0.11 & $(0.12)$ & 0.10 & $(0.07)$ \\
\hline $50-54$ & 0.05 & $(0.09)$ & 0.12 & $(0.14)$ & 0.07 & $(0.08)$ \\
\hline $55-59$ & 0.01 & $(0.10)$ & 0.09 & $(0.15)$ & 0.04 & $(0.09)$ \\
\hline $\begin{array}{l}\text { Employment status } \\
\text { (ref.: non-employed) }\end{array}$ & & & & & & \\
\hline Full-time & $0.11 * * *$ & $(0.03)$ & $0.12 * * *$ & $(0.03)$ & $0.11 * * *$ & $(0.02)$ \\
\hline Part-time & 0.03 & $(0.03)$ & 0.05 & $(0.04)$ & 0.03 & $(0.02)$ \\
\hline In education & -0.04 & $(0.05)$ & 0.04 & $(0.06)$ & -0.01 & $(0.04)$ \\
\hline $\begin{array}{l}\text { Marginally } \\
\text { (log) net equivalent }\end{array}$ & 0.04 & $(0.03)$ & -0.02 & $(0.06)$ & 0.03 & $(0.03)$ \\
\hline $\begin{array}{l}\text { income } \\
\text { Education } \\
\text { (ref.: ISCED 3-4 Middle) }\end{array}$ & $0.11 * * *$ & $(0.02)$ & $0.15^{* * *}$ & $(0.04)$ & $0.12 * * *$ & $(0.02)$ \\
\hline ISCED 0-2 LOW & -0.01 & $(0.04)$ & -0.11 & $(0.07)$ & -0.04 & $(0.04)$ \\
\hline ISCED 5-6 High & 0.03 & $(0.04)$ & -0.03 & $(0.07)$ & 0.02 & $(0.03)$ \\
\hline Constant & $6.53^{* * *}$ & $(0.21)$ & $6.13^{* * *}$ & $(0.35)$ & $6.42 * * *$ & $(0.18)$ \\
\hline Observations & 119144 & & 50300 & & 169444 & \\
\hline $\mathrm{R}^{2}$ & 0.04 & & 0.05 & & 0.04 & \\
\hline
\end{tabular}

Standard errors in parentheses; * $p \varangle 0.05, * * p \varangle 0.01, * * * p \varangle 0.001$ 